PREPARED FOR THE U.S. DEPARTMENT OF ENERGY, UNDER CONTRACT DE-AC02-76CH03073

PPPL-3705

PPPL-3705

UC-70

Neutral Transport Simulations of Gas Puff Imaging Experiments on Alcator C-Mod

by

D.P. Stotler, B. LaBombard, J.L. Terry, and S.J. Zweben

June 2002

NM|

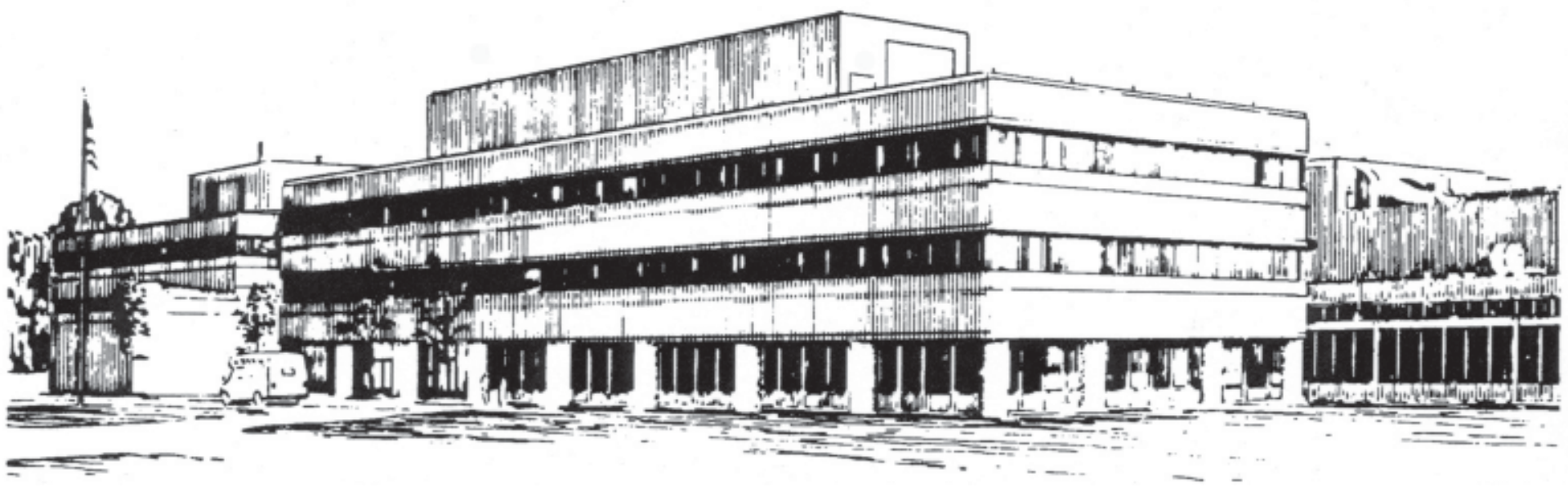

PRINCETON PLASMA PHYSICS LABORATORY PRINCETON UNIVERSITY, PRINCETON, NEW JERSEY 


\section{PPPL Reports Disclaimer}

This report was prepared as an account of work sponsored by an agency of the United States Government. Neither the United States Government nor any agency thereof, nor any of their employees, makes any warranty, express or implied, or assumes any legal liability or responsibility for the accuracy, completeness, or usefulness of any information, apparatus, product, or process disclosed, or represents that its use would not infringe privately owned rights. Reference herein to any specific commercial product, process, or service by trade name, trademark, manufacturer, or otherwise, does not necessarily constitute or imply its endorsement, recommendation, or favoring by the United States Government or any agency thereof. The views and opinions of authors expressed herein do not necessarily state or reflect those of the United States Government or any agency thereof.

\section{Availability}

This report is posted on the U.S. Department of Energy's Princeton Plasma Physics Laboratory Publications and Reports web site in Fiscal Year 2002. The home page for PPPL Reports and Publications is: http://www.pppl.gov/pub_report/

DOE and DOE Contractors can obtain copies of this report from:

U.S. Department of Energy

Office of Scientific and Technical Information

DOE Technical Information Services (DTIS)

P.O. Box 62

Oak Ridge, TN 37831

Telephone: (865) 576-8401

Fax: (865) 576-5728

Email: reports@adonis.osti.gov

This report is available to the general public from:

National Technical Information Service

U.S. Department of Commerce

5285 Port Royal Road

Springfield, VA 22161

Telephone: 1-800-553-6847 or

(703) 605-6000

Fax: (703) 321-8547

Internet: http://www.ntis.gov/ordering.htm 


\title{
Neutral transport simulations of gas puff imaging experiments on Alcator C-Mod
}

\author{
D.P. Stotler ${ }^{\text {a }}$ B. LaBombard ${ }^{\text {b }}$ J.L. Terry ${ }^{\text {b }}$, and S.J. Zweben ${ }^{\text {a }}$, \\ ${ }^{a}$ Princeton Plasma Physics Laboratory, Princeton University, P. O. Box 451, \\ Princeton, NJ 08543-0451, USA \\ ${ }^{\mathrm{b}}$ MIT Plasma Science and Fusion Center, NW17, Cambridge, MA 02139, USA
}

\begin{abstract}
Visible imaging of gas puffs has been used on the Alcator C-Mod tokamak to characterize edge plasma turbulence, yielding data that can be compared with plasma turbulence codes. Simulations of these experiments with the DEGAS 2 Monte Carlo neutral transport code have been carried out to explore the relationship between the plasma fluctuations and the observed light emission. By imposing two-dimensional modulations on the measured time-average plasma density and temperature profiles, we demonstrate that the spatial structure of the emission cloud reflects that of the underlying turbulence. However, the photon emission rate depends on the plasma density and temperature in a complicated way, and no simple scheme for inferring the plasma parameters directly from the light emission patterns is apparent. The simulations indicate that excited atoms generated by molecular dissociation are a significant source of photons, further complicating interpretation of the gas puff imaging results.
\end{abstract}

Key words: Alcator C-Mod, Turbulence, Neutral gas modeling, DEGAS code PACS:

\section{Introduction}

The edge plasma of the tokamak is ideal for a comprehensive study of plasma turbulence. First, the relatively low electron densities and temperatures as well as the location make the edge plasma accessible to study with reciprocating probes. Second, the low temperatures also allow atomic physics processes to be used as the basis for diagnostics. The potential benefit of understanding turbulence in the edge plasma is great since the boundary conditions for the core plasma are set in or near this region.

Preprint submitted to Elsevier Science 6th June 2002 
The gas puff imaging (GPI) diagnostic[1,2,3] is designed to exploit these prospects and to provide two-dimensional (2-D) data on the structure of the plasma turbulence for comparison with three-dimensional (3-D) nonlinear plasma simulation codes and with direct probe measurements of the turbulence characteristics. The GPI diagnostic consists of recording with high temporal and spatial resolution [1] the light generated by neutral atoms puffed into the edge of the plasma. The experiments considered in this paper use deuterium as the working gas.

The relationship between the camera images and the underlying plasma fluctuations can be explored in a straightforward way with the Monte Carlo neutral transport code DEGAS 2 [4]. The number of molecules puffed is small enough to not significantly perturb the plasma [1]. Yet, the emitted light is much brighter than that arising from background neutral species [1]. Hence, the latter need not be simulated. Furthermore, material surface interactions should not be important.

\section{Description of Simulations}

The Alcator C-Mod geometry used in DEGAS 2 is built up from a simple outline of the vacuum vessel, including the gas puff nozzle and surrounding structures, and an equilibrium computed for the shot and time of interest. A 2-D plasma mesh is established using the DG and CARRE packages [5]. The volume between the plasma mesh and the material surfaces is broken up into triangles [6]. The mesh zones in the emission region have linear dimensions on the order of a few millimeters. The input geometry and plasma data are toroidally symmetric. All of the output data are averaged over toroidal angle. The principal quantity for comparison with the experimental images is the Balmer- $\alpha\left(D_{\alpha}\right)$ photon intensity in the poloidal plane. Toroidal resolution will be added in future work, and the GPI camera views will be modeled directly. This will allow a quantitative comparison of the image intensity and an evaluation of the spatial averaging caused by the finite toroidal extent of the emission cloud.

These DEGAS 2 simulations are time-independent. The radiative decay time of the upper level of the emitting transition $(n=3)$ is $<0.02 \mu \mathrm{s}$, much shorter than the autocorrelation time for the turbulence of $10-20 \mu \mathrm{s}$ [1]. The time required for a $3 \mathrm{eV}$ (a typical dissociation energy) atom to cross the emission cloud is about $1 \mu \mathrm{s}$, also short enough for the steady state assumption to be valid. Time-dependent neutral transport will be investigated in subsequent work.

The deuterium atomic and molecular physics processes incorporated into these 
simulations have been described elsewhere [7,8]. Balmer- $\alpha$ photons resulting from $\mathrm{D}_{2}$ dissociation are included using the reactions, rates, and kinetics given in Ref. [8]. Neutral-neutral collisions are not included in these simulations, even though they may not be negligible. To treat them correctly, we would need a realistic value for the neutral densities and, hence, a toroidally resolved calculation modeling the 3-D expansion of the gas flowing away from the nozzle.

The emission rate of the observed light in $\mathrm{m}^{-3} \mathrm{~s}^{-1}$ is computed by an expression equivalent to

$$
S_{\mathrm{D}_{\alpha}}=\sum_{j=\mathrm{D}, \mathrm{D}_{2}, \mathrm{D}_{2}^{+}} n_{j} f_{j}\left(n_{e}, T_{e}\right)
$$

where $n_{j}$ is the computed density of the electronic ground state atom, molecule or molecular ion. The function $f_{D}$ is the ratio of the density of the upper level of the radiative transition to the ground state density times the Einstein coefficient for the transition. The local distribution of neutral atoms over the electronically excited states is provided by a collisional-radiative model [7] and read into DEGAS 2 as tabular data. The relationship between the plasma fluctuations and the light intensity is largely determined by the $n_{e}$ and $T_{e}$ dependence of $f_{D}$. For $\mathrm{D}_{2}$ and $\mathrm{D}_{2}^{+}, f_{j}$ is the electron density times the sum of the rates of the reactions that result in an atom in the $n=3$ state [8].

All simulated gas puffs have a temperature of $300 \mathrm{~K}$ with a cosine distribution for the angle normal to the surface of the gas nozzle. Preliminary simulations with a $150 \mathrm{~K}$ puff and with a $(\cos \theta)^{4}$ angular distribution yielded emission clouds having the same peak location and radial half-width. The peaked angular distribution did produce an emission region with a smaller vertical half-width.

Time-average radial profiles of the plasma density and temperature are provided by a midplane reciprocating probe. The data are mapped onto the DEGAS 2 mesh by assuming that the density and temperature are constant on a flux surface and $n_{i}=n_{e}$ and $T_{i}=T_{e}$. In the triangulated region of the computational mesh, the radial coordinate is estimated as the physical distance between the zone center and the nearest zone of the flux surface-based mesh.

\section{Results}

The simulations described here are based on Alcator C-Mod shot 1010622006 at $700 \mathrm{~ms}$. Over the emission region, $T_{e}$ varies between 10 and $60 \mathrm{eV} ; n_{e}$ ranges from $1 \times 10^{19} \mathrm{~m}^{-3}$ to $8 \times 10^{19} \mathrm{~m}^{-3}$. The $\mathrm{D}_{\alpha}$ emission pattern computed from 
the time-average plasma profiles is shown in Fig. 1. This result is compared with the time-average experimental GPI images in Ref. [1].

The small emission peak directly in front of the gas nozzle is not observed experimentally and will be ignored here. The probe data extend only out to $R=0.91 \mathrm{~m}$ for this shot and are assumed constant at larger radii. The magnitude of this peak would be reduced by more than two orders of magnitude if $T_{e}<2.5 \mathrm{eV}$ or if $n_{e}<3.6 \times 10^{16} \mathrm{~m}^{-3}$. Both possibilities are consistent with an exponential extrapolation of the outermost probe data points.

Molecular processes contribute roughly $40 \%$ of the photons at the peak of the primary cloud. This fraction falls to $<10 \%$ for $R \lesssim 0.9 \mathrm{~m}$. The magnitude of the molecular emission is larger than expected; this result should be validated experimentally.

The contours in Fig. 1 indicate the fraction of atoms that have experienced a charge exchange collision. About $10-20 \%$ of the atoms have undergone reflection at a material surface. The remaining fraction have not struck a material surface or charge exchanged since being created by a dissociation event and, hence, have traveled ballistically from that event. Most of the D emission comes from such atoms.

We investigate the relationship between the instantaneous plasma profiles and the observed emission patterns by imposing on the time-average electron (and ion) density and temperature ad hoc density and temperature modulations,

$$
n_{e}^{\prime}(R, Z)=n_{e}(R, Z)\left[1+\frac{1}{2} \sin \left(\frac{\pi Z}{0.01}\right)\right]\left\{1+\frac{1}{2} \sin \left[\frac{\pi\left(R-R_{\text {sep }}+0.0035\right)}{0.005}\right]\right\},(2)
$$

This results in a $0.02 \mathrm{~m}$ wavelength for the poloidal variation [1]. The smaller radial wavelength of $0.01 \mathrm{~m}$ allows a full period of the modulation to fit inside the emission cloud. The radial shift of $0.0035 \mathrm{~m}$ permits the innermost density point to have the same value as in the unperturbed case. The resulting 2D emission contours is shown in Fig. 2(a). In a separate run, we apply the same perturbation to the electron and ion temperatures; the temperatures are constrained to be between 5 and $100 \mathrm{eV}$. The effect of the $T_{i}$ perturbation is expected to be small since $T_{i}$ only enters through the neutral-ion elastic scattering processes. Figure. 3 shows a vertical slice through the $\mathrm{D}_{\alpha}$ emission cloud, normalized to the unperturbed result, obtained in these two runs. The radius of the slice, $R=0.904 \mathrm{~m}$, has been chosen to pass through a peak in the radial variation of Eq. (2).

The simulated emission patterns show the same 2-D structure as the underlying density (or temperature) perturbation. Hence, we anticipate that a poloidal analysis of the experimentally observed emission pattern will yield a spectrum 
that is at least similar to that of the underlying turbulence. Note that we expect the autocorrelation functions and frequency spectra computed from the GPI images to also mirror those of the plasma. Subsequent investigations will attempt to quantitatively verify these assertions.

The magnitude of the maxima of the normalized $\mathrm{D}_{\alpha}$ quantities in Fig. 3 are smaller than those of the applied modulations because the density and temperature dependencies of the function $f_{\mathrm{D}}$ in Eq. (1) are less than linear. The value of $\partial \ln f_{\mathrm{D}} / \partial \ln T_{e}$ varies between 0.3 at $R=0.89 \mathrm{~m}$ and 1.4 at $R=0.91$ $\mathrm{m}$. Likewise, $\partial \ln f_{\mathrm{D}} / \partial \ln n_{e}$ rises from 0.5 to 0.8 over the same radial range. At the $\mathrm{D}_{\alpha}$ peak, $R=0.905 \mathrm{~m}, \partial \ln f_{\mathrm{D}} / \partial \ln T_{e}=0.7$ and $\partial \ln f_{\mathrm{D}} / \partial \ln n_{e}=0.6$.

The structure of Fig. 3 and the relationship between the normalized modulation and emission amplitudes are more complicated than those displayed in the analogous figure of Ref. [1] because of the inclusion here of molecular contributions to Eq. (1). The density dependence of $f_{\mathrm{D}_{2}}$ and $f_{\mathrm{D}_{2}^{+}}$is explicitly linear. Because three different processes contribute to these functions and because of the strong correlation between $n_{\mathrm{D}}$ and $n_{\mathrm{D}_{2}}$, the temperature dependence of the molecular contributions to Eq. (1) is complicated. Like $f_{\mathrm{D}}$, their effective temperature scaling will vary radially.

The simplest interpretation of the GPI technique is that the emission patterns primarily reflect electron density fluctuations and that the emission rate is insensitive to temperature fluctuations. This would be valid if $n_{e} \lesssim 10^{18}$ $\mathrm{m}^{-3}$ and $T_{e} \gg 10 \mathrm{eV}$. Under conditions typical of the Alcator C-Mod edge, however, the density and temperature dependencies of the emission rate are not sufficiently different to allow the perturbed plasma density or temperature to be inferred directly from the GPI images. Inversion of the data would be simpler if the electron density and temperature perturbations were in phase, as some theories predict.

The preceding arguments have discussed only the effect of the plasma fluctuations on the functions $f_{j}$, even though they also impact the neutral densities. A "shadowing effect" exists in which the ionization of the puffed atoms caused by a localized $n_{e}$ or $T_{e}$ peak reduces the light fluctuations at smaller radii.

Consider two emission patterns. The first, with the shadowing, is obtained with the perturbed plasma profiles in the manner described above [e.g., Fig. 2(a)]. The second is assembled during post-processing using the perturbed values of the $f_{j}$ and the unperturbed $n_{j}$, eliminating the shadowing. The resulting image from the run with perturbed $n_{e}$ is presented in Fig. 2(b). Figure 2(b) more clearly reflects the structure of the imposed $n_{e}$ perturbation. The pattern in Fig. 2(a) is smeared out not only due to neutral densities reduced by $n_{e}$ peaks, but also to neutral densities increased by $n_{e}$ minima (see also Fig. 3 ). To estimate the magnitude of the shadowing, we normalize the difference of 
these two images to the unperturbed emission rate:

$$
F_{s}=\left[\sum_{j}\left(n_{j}^{\prime}-n_{j}\right) f_{j}^{\prime}\right] / \sum_{j} n_{j} f_{j},
$$

The primes indicate the value obtained with perturbed plasma parameters. We have computed $F_{s}$ for both of the simulations with perturbed plasma parameters.

Space does not permit 2-D plots of $F_{s}$ to be shown or explained in detail. Instead, we note only that $\left|F_{s}\right| \gtrsim 0.5$ over a significant area and that most of this is due to the molecular contributions. The cause is a greater sensitivity of the molecular density to the plasma parameters. In contrast, the analogous shadowing fraction based on the photons from $\mathrm{D}$ alone varies between -0.2 and 0.2 over the emission region. We conclude that quantitatively interpreting the GPI images will require not only taking into account the density and temperature dependencies of the $f_{j}$ functions of Eq. (1), but also the effect of the plasma fluctuations on the neutral densities. Neutral transport codes such as DEGAS 2 can facilitate these interpretations, but careful benchmarks of the atomic and molecular models in the code will have to be carried out first. Such simulations will be the subject of a subsequent paper.

\section{Acknowldegments}

This work supported by U.S. DOE Contracts DE-AC02-CHO3073 and DEFC02-99ER54512.

\section{References}

[1] S. J. Zweben, D. P. Stotler, J. L. Terry, B. LaBombard, M. Greenwald, M. Muterspaugh, C. S. Pitcher, the Alcator C-Mod Group, K. Hallatschek, R. J. Maqueda, B. Rogers, J. L. Lowrance, V. J. Mastrocola, G. F. Renda, Edge turbulence imaging in the alcator c-mod tokamak, Phys. Plasmas 9 (2002) 1981-1989.

[2] R. J. Maqueda, G. A. Wurden, S. Zweben, L. Roquemore, H. Kugel, D. Johnson, S. Kaye, S. Sabbagh, R. Maingi, Edge turbulence measurements in nstx by gas puff imaging, Rev. Sci. Instrum. 72 (2001) 931-934.

[3] J. L. Terry, R. Maqueda, C. S. Pitcher, S. J. Zweben, B. LaBombard, E. S. Marmar, A. Y. Pigarov, G. Wurden, Visible imaging of turbulence in the sol of the alcator c-mod tokamak, J. Nucl. Mater. 290-293 (2001) 757-762. 
[4] D. P. Stotler, C. F. F. Karney, Neutral transport modeling with degas 2, Contrib. Plasma Phys. 34 (1994) 392-397.

[5] D. P. Coster, private communication (1999).

[6] Applied Computational Geometry: Towards Geometric Engineering, Vol. 1148, Springer, New York, 1996, p. 203.

[7] D. P. Stotler, C. S. Pitcher, C. J. Boswell, T. K. Chung, B. LaBombard, B. Lipschultz, J. L. Terry, R. J. Kanzleiter, Modeling of alcator c-mod divertor baffling experiments, J. Nucl. Mater. 290-293 (2001) 967-971.

[8] D. P. Stotler, C. H. Skinner, R. V. Budny, A. T. Ramsey, D. N. Ruzic, R. B. Turkot, Jr., Modeling of neutral hydrogen velocities in the tokamak fusion test reactor, Phys. Plasmas 3 (1996) 4084-4094. 


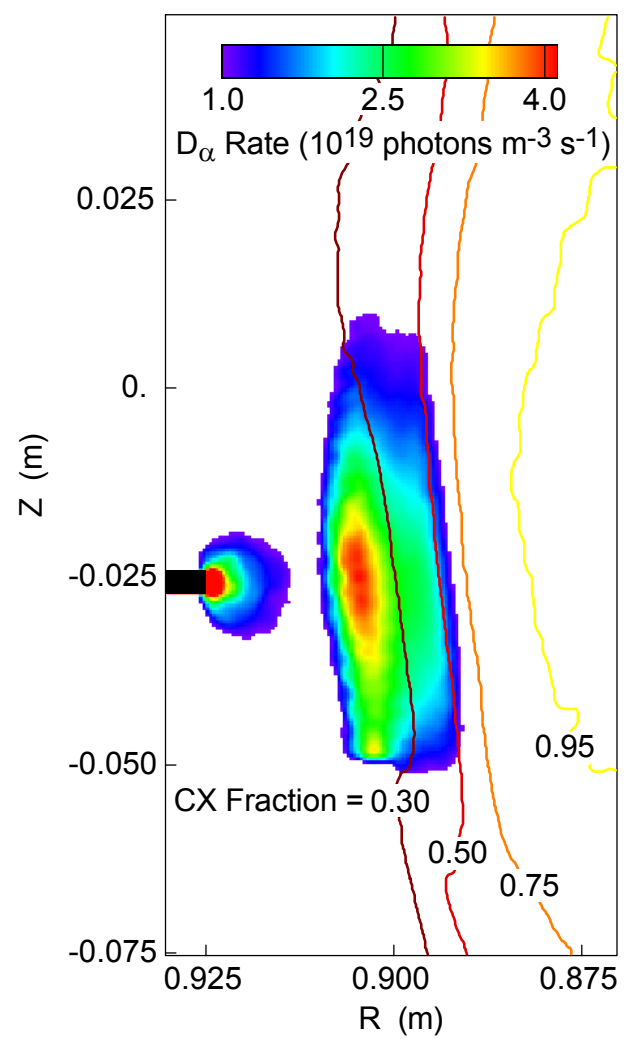

Figure 1. Balmer- $\alpha$ emission pattern from the baseline DEGAS 2 simulation using the time-average profiles measured by the reciprocating probe. The gas puff nozzle is indicated in black. The contour lines give the fraction of atoms at that location that have experienced a charge exchange. 

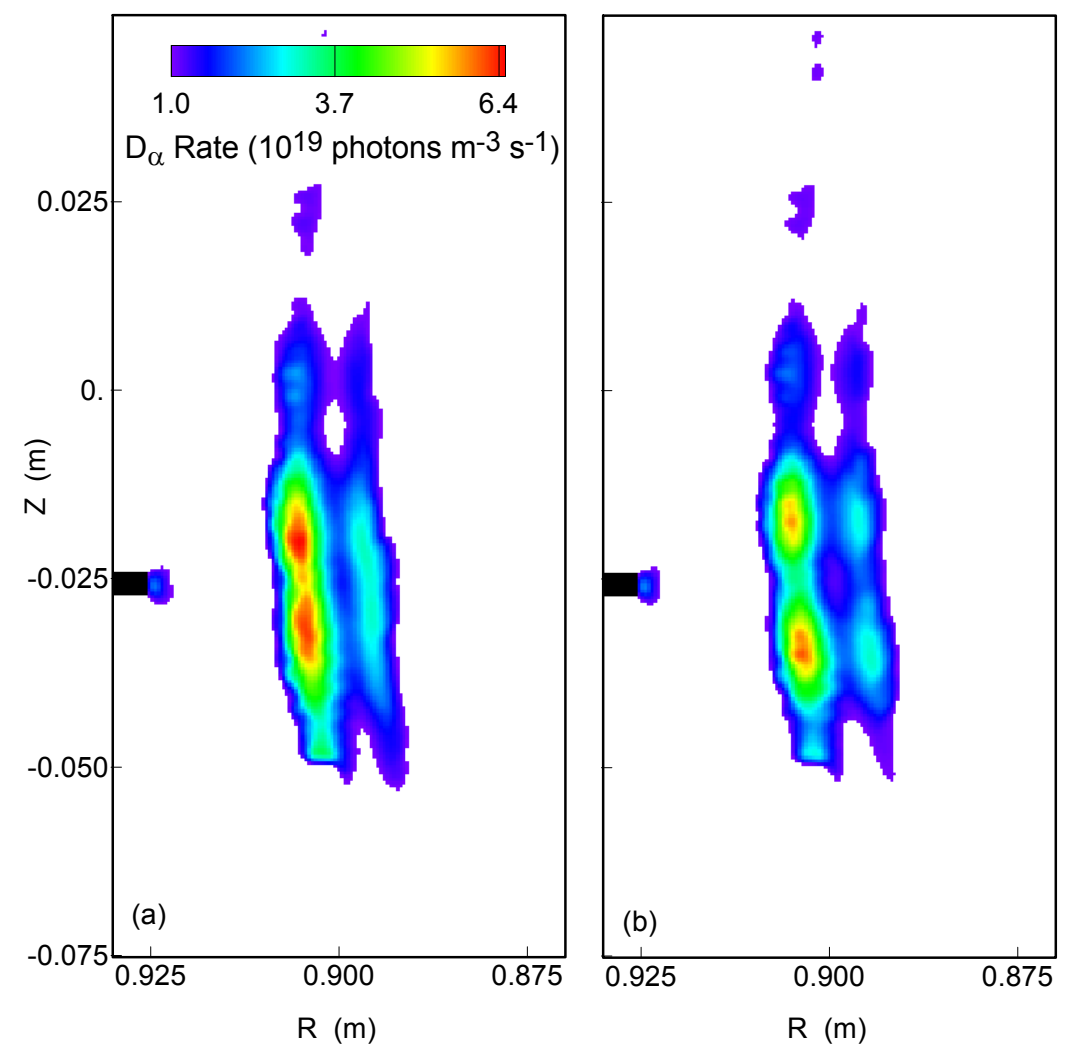

Figure 2. Balmer- $\alpha$ emission patterns from DEGAS 2 simulation with the electron density perturbation [Eq. (2)]. The frame labeled (a) is the result produced directly by the code and, thus, incorporates the "shadowing" effect of the perturbation on the neutral densities. Frame (b) has been assembled in post-processing to eliminate the shadowing effect. Both plots are drawn using the scale shown in (a). 


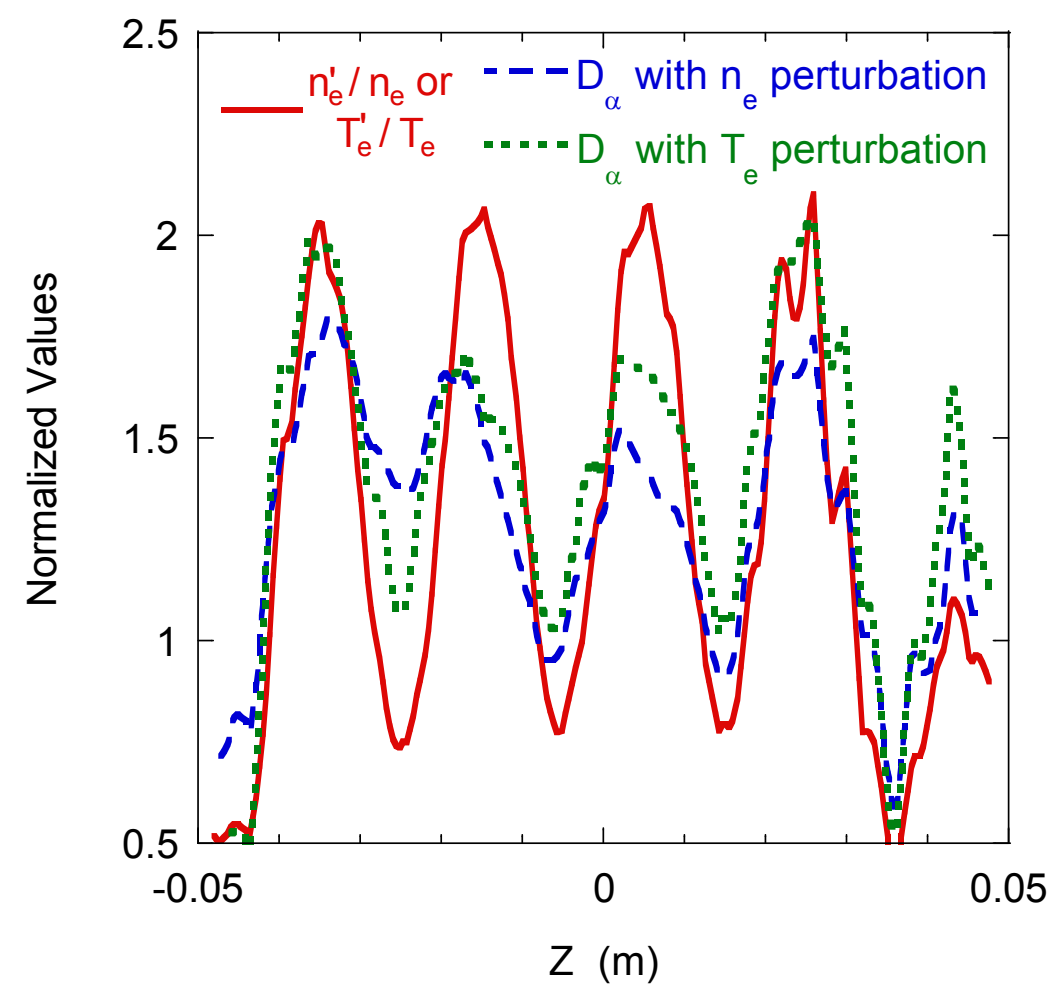

Figure 3. Vertical variation of the applied plasma parameter modulation [Eq. (2)] and the resulting $\mathrm{D}_{\alpha}$ emission patterns normalized to the values obtained in the baseline simulation. This vertical slice is taken at $R=0.904 \mathrm{~m}$. 


\section{External Distribution}

Plasma Research Laboratory, Australian National University, Australia

Professor I.R. J ones, Flinders University, Australia

Professor J oão Canalle, Instituto de Fisica DEQ/IF - UERJ , Brazil

Mr. Gerson O. Ludwig, Instituto Nacional de Pesquisas, Brazil

Dr. P.H. Sakanaka, Instituto Fisica, Brazil

The Librarian, Culham Laboratory, England

Library, R61, Rutherford Appleton Laboratory, England

Mrs. S.A. Hutchinson, JET Library, England

Professor M.N. Bussac, Ecole Polytechnique, France

Librarian, Max-Planck-Institut für Plasmaphysik, Germany

J olan Moldvai, Reports Library, MTA KFKI-ATKI, Hungary

Dr. P. Kaw, Institute for Plasma Research, India

Ms. P.J . Pathak, Librarian, Insitute for Plasma Research, India

Ms. Clelia De Palo, Associazione EURATOM-ENEA, I taly

Dr. G. Grosso, Instituto di Fisica del Plasma, Italy

Librarian, Naka Fusion Research Establishment, J AERI, J apan

Library, Plasma Physics Laboratory, Kyoto University, J apan

Research Information Center, National Institute for Fusion Science, J apan

Dr. O. Mitarai, Kyushu Tokai University, J apan

Library, Academia Sinica, Institute of Plasma Physics, People's Republic of China

Shih-Tung Tsai, Institute of Physics, Chinese Academy of Sciences, People's Republic of China

Dr. S. Mirnov, TRINITI, Troitsk, Russian Federation, Russia

Dr. V.S. Strelkov, Kurchatov Institute, Russian Federation, Russia

Professor Peter Lukac, Katedra Fyziky Plazmy MFF UK, Mlynska dolina F-2, Komenskeho Univerzita, SK-842 15 Bratislava, Slovakia

Dr. G.S. Lee, Korea Basic Science Institute, South Korea

Mr. Dennis Bruggink, Fusion Library, University of Wisconsin, USA

Institute for Plasma Research, University of Maryland, USA

Librarian, Fusion Energy Division, Oak Ridge National Laboratory, USA

Librarian, Institute of Fusion Studies, University of Texas, USA

Librarian, Magnetic Fusion Program, Lawrence Livermore National Laboratory, USA

Library, General Atomics, USA

Plasma Physics Group, Fusion Energy Research Program, University of California at San Diego, USA

Plasma Physics Library, Columbia University, USA

Alkesh Punjabi, Center for Fusion Research and Training, Hampton University, USA

Dr. W.M. Stacey, Fusion Research Center, Georgia Institute of Technology, USA

Dr. J ohn Willis, U.S. Department of Energy, Office of Fusion Energy Sciences, USA

Mr. Paul H. Wright, Indianapolis, Indiana, USA 
The Princeton Plasma Physics Laboratory is operated by Princeton University under contract with the U.S. Department of Energy.

\author{
Information Services \\ Princeton Plasma Physics Laboratory \\ P.O. Box 451 \\ Princeton, NJ 08543
}

Phone: 609-243-2750

Fax: 609-243-2751

e-mail: pppl_info@pppl.gov

Internet Address: http://www.pppl.gov 